\title{
An ultrastructural study of the effect of neomycin on the colon in the human subject and in the conventional and the germ-free mouse
}

\author{
A. P. R. AlUWIHARE \\ From the Anatomy Department, Royal College of Surgeons of England, London
}

SUMMARY An electron microscopic study of the colon of normal mice and human subjects and those treated with neomycin is reported; there is a close resemblance between the mouse and human colons. After rapid disinfection of the colon, there is epithelial cell damage due to a toxic effect of the drug, a reduction in epithelial turnover accompanying the change in flora, and an important reduction in the cellularity of the lamina propria mainly due to a reduction in inflammatory cells.

The changes in the lamina propria probably represent changes in the antipathogenetic defences of the host.

This paper describes a study of the effect of neomycin on the fine structure of the colon. The study was undertaken because conflicting reports exist on the need for the use of antibiotics and the occurrence of serious side effects following their use in the preoperative preparation of the colon (Lancet, 1970). An attempt was made to determine whether there were structural changes that might reveal the morphological basis of the defence mechanisms of the colon and whether or not these are affected by the short-term use of neomycin. A full description and evaluation of the methods and results is given by Aluwihare (1969).

\section{Material}

Conventional and germ-free mice of the same substrain of the $\mathrm{C} 3 \mathrm{H}$ strain, 8 to 12 weeks old, were used. Microscopically normal specimens were taken from the sigmoid colon of patients undergoing resections for carcinoma.

\section{Methods}

\section{LIGHT MICROSCOPY}

Specimens were taken from the area adjacent to that studied by electron microscopy, and processed by standard methods (Davenport, 1960).

Received for publication 11 December 1970.
ELECTRON MICROSCOPY

Specimens, from the 'sigmoid' colon of the anaesthetized, moribund mouse were fixed immediately in ice-cold $1 \%$ buffered osmium tetroxide. The human material was taken from viable cut ends of bowel immediately before anastomosis and fixed within one minute of removal. The processing was based on the account of Causey (1962). Acid phosphatase was demonstrated by Gomori's technique (Corrin, Clarke, and Spencer, 1969). The sections were examined unstained in an AEI EM6 microscope.

\section{BACTERIOLOGY}

Ten-fold dilutions of faeces in Ringer's solution were used with a drop counting method on blood and MacConkey agar plates (Baker and Bream, 1967). Anaerobes were counted by Parker's method (1965).

ESTIMATION OF THE CELLULARITY OF THE LAMINA PROPRIA

Using the electron microscope over $90 \%$ of the nucleated cells in the lamina propria could be identified at a magnification of $\times 6,000$. Cellularity ${ }^{1}$ was estimated by obtaining the ratio of 'other' cells to endothelial cells for each mouse, 500-1,000 cells being counted per animal. The assumption that the ${ }^{1}$ Cellularity $=$ no. of cells/unit volume of lamina propria. 
number of endothelial cells per unit volume of lamina propria is constant during the experiments is supported by the observation that, where there are clear increases in the numbers of other cells in the infected germ-free mice and the inflamed human colons, there is a decrease in the proportion of endothelial cells.

As a complementary method of light microscopy an eyepiece graticule with $0.25 \mathrm{~mm}$ squares was used to count the number of cells in any field that fell over the lamina propria; then the nuclei in the same area were counted. The ratio of nuclei to squares gives the cellularity; the sections were $5 \pm 1 \mathrm{~m} \mu$ thick. About 500 squares were counted for each mouse, giving a relative standard error of $\pm 2 \%$ for each group (Hally, 1964).

If the same result is obtained by both methods it represents an actual change in the cell content of the lamina propria, because the techniques have different sources of error (Aluwihare, 1969).

\section{STATISTICS}

Care was taken to eliminate uncontrolled variables by using matched and adequate controls, random selection of animals, and conducting experiments concurrently (Bradford-Hill, 1966).

\section{The Experimental Groups}

Five control (conventional) mice with $38 \times 10^{6}$ $\left(\mathrm{SE} \pm 15 \times 10^{6}\right)$ aerobic bacteria/g wet faeces on MacConkey plates, 4 to $250 \times 10^{6}$ being coliforms; there were over $10^{8}$ anaerobes $/ g$ wet faeces. The number did not vary more than ten-fold over several days and was not affected by the intragastric administration of water; neither was the faecal consistency.

Five treated (conventional) mice were given two intragastric doses of neomycin sulphate BP starting 20 hours before death. The minimum doses needed to disinfect the bowel were an initial one of $1,000 \mathrm{mg} / \mathrm{kg}$ and one of $500 \mathrm{mg} / \mathrm{kg}$ four hours before death. At the time of death the anaerobic count was about $10^{4} \mathrm{~g} /$ wet faeces; no aerobic bacteria could be isolated either on plate or in broth cultures.
Four germ-free (control) mice were killed on arrival.

One treated (germ-free) mouse was given two intragastric doses of neomycin sulphate BP starting 20 hours before death.

Four infected germ-free mice (gnotobiotes) were given a faecal suspension and killed between 20 and 28 hours later. There were over $2,000 \times 10^{6}$ staphylococci/g wet faeces at death.

Three mice, treated for 28 hours, and killed 28 hours after the first dose of neomycin had colons infected with staphylococci.

Four subjects (controls) with normal faecal flora formed one group.

Of two subjects treated with neomycin, one was disinfected and the other infected with staphylococci.

Of a further three subjects, two had Crohn's disease and one ulcerative colitis.

Studies of epithelial mitotic rates (LeBlond and Stevens, 1948) were done in three groups of mice. (1) Five control (conventional) mice given $0 \cdot 1 \mathrm{mg}$ colchicine subcutaneously were killed five hours later. (2) Six treated (conventional) mice given colchicine at the time of the second dose of neomycin were killed five hours later. (3) Five control and tive treated (germ-free) mice were given colchicine as in (1) and (2) above; these mice remained sterile.

Sections from the sigmoid colon were cut $7 \mathrm{~m} \mu$ thick, and examined at a magnification of $\times 600$. The number of mitotic and normal nuclei were counted in two batches of about 600 nuclei each for every mouse.

\section{Results}

\section{LAMINA PROPRIA}

The changes here seem more relevant to clinical practice.

The cell classification in the Table (Aluwihare, 1969) is based on the data of Zweifach, Grant, and McCluskey (1965) and others. Lymphocytes and plasma cells, seen throughout the lamina propria, are often close to each other and to macrophages (Fig. 1) but without cytoplasmic continuity. Granular leucocytes are seen less frequently. Endothelial cells are

\begin{tabular}{|c|c|c|c|c|c|c|c|c|c|}
\hline \multirow[t]{2}{*}{ Specimen } & \multirow{2}{*}{$\begin{array}{l}\text { No. of } \\
\text { Specimens }\end{array}$} & \multirow{2}{*}{$\begin{array}{l}\text { Total No. } \\
\text { of Cells }\end{array}$} & \multicolumn{7}{|c|}{ Type of Cell (\% of Total) } \\
\hline & & & $\begin{array}{l}\text { Fibroblasts, } \\
\text { Unclassified, } \\
\text { Schwann, and } \\
\text { Vesicular } \\
\text { Cells }\end{array}$ & Macrophages 1 & Mast Cells & $\begin{array}{l}\text { Endothelial } \\
\text { Cells }\end{array}$ & Plasma Cells & Lymphocytes & Granulocytes \\
\hline $\begin{array}{l}\text { Human } \\
\text { Mouse }\end{array}$ & $\begin{array}{l}4 \\
5\end{array}$ & $\begin{array}{l}2,104 \\
3,483\end{array}$ & $\begin{array}{l}42 \\
48\end{array}$ & $\begin{array}{l}10 \\
10\end{array}$ & $\begin{array}{l}<1 \\
<1\end{array}$ & $\begin{array}{l}7 \\
8\end{array}$ & $\begin{array}{l}15 \\
10\end{array}$ & $\begin{array}{l}16 \\
14\end{array}$ & $\begin{array}{l}10 \\
10\end{array}$ \\
\hline
\end{tabular}

Table The proportion of cells in the lamina propria of mouse and human sigmoid colons with normal flora 


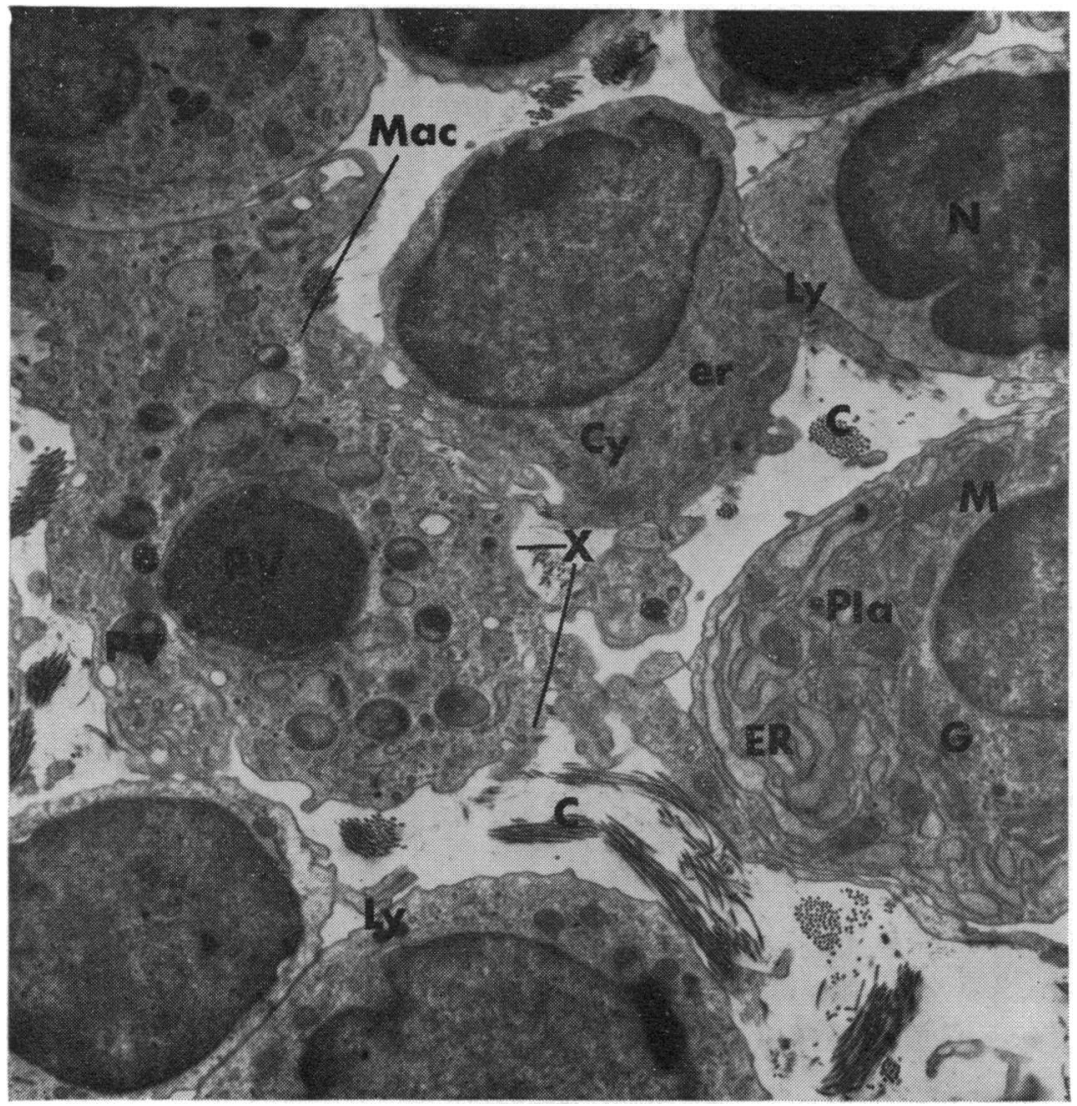

Fig. 1 Lamina propria of the mouse colon showing parts of macrophages (Mac), lymphocytes (Ly), and a plasma cell (Pla). $(\times 7,500$.) $\mathrm{PV}=$ phagocytic vesicle; $\mathrm{x}=$ ragged edge of macrophage; $\mathrm{ER}=$ endoplasmic reticulum; $\mathbf{M}=$ mitochondria; $\mathbf{G}=$ Golgi zone; $\mathrm{N}=$ nucleus; $\mathrm{C}=$ collagen. The central lymphocyte has cytoplasmic (Cy) features of transformation (er).

associated with the lumen of a vessel and a basement membrane. Figure 2 shows a macrophage near the human luminal epithelium and a lymphocyte between epithelial cells. Figure 3 shows a subepithelial fibroblast, a mast cell, nerve bundles, and fibrous tissue. The unclassified group consists of cells which could be either fibroblasts, macrophages, or stem cells. The morphology and the proportions of cells in the lamina propria is strikingly similar in the mouse and human subject (Table).

The arrangement of structures, for example the thickness of the supepithelial fibrous layer, is subject to considerable variation. There are nerves everywhere (Figs. 2 and 3). These arrangements and the fine structure of the deeper layers of the colon are similar in all the groups of mice and human subjects.

In the treated mouse the light microscope does not reveal any focal changes, for example, in vascularity or Peyer's patches. The lamina propria is probably less cellular. In the germ-free mouse it is almost acellular.

After neomycin, many plasma cells have distended endoplasmic reticulum and swollen mitochondria. The content of the macrophages is qualitatively unchanged. In the gnotobiote there are cells with many clear vesicles without acid phosphatase. These appear to change into macrophages when the mouse is infected. The basement membranes are unchanged. The interesting changes are quantitative.

The use of the graticule and the electron microscope have shown independently that there is a significant reduction in the cellularity of the lamina propria 20 hours after beginning treatment with neomycin, at a time when aerobic bacteria could not be isolated from the faeces (Fig. 4). The changes are due mainly to alterations in the proportions of mobile cells (lymphocytes, plasma cells, neutrophil and eosinophil leucocytes). The dramatic changes in the actual numbers of mobile cells, using the ratio of mobile cells to endothelial cells, are shown in Figure 5. The reverse changes occur when germ-free mice are infected. The macrophages behave like mobile cells. The reduction in mobile cells after neomycin occurs mainly with respect to the 


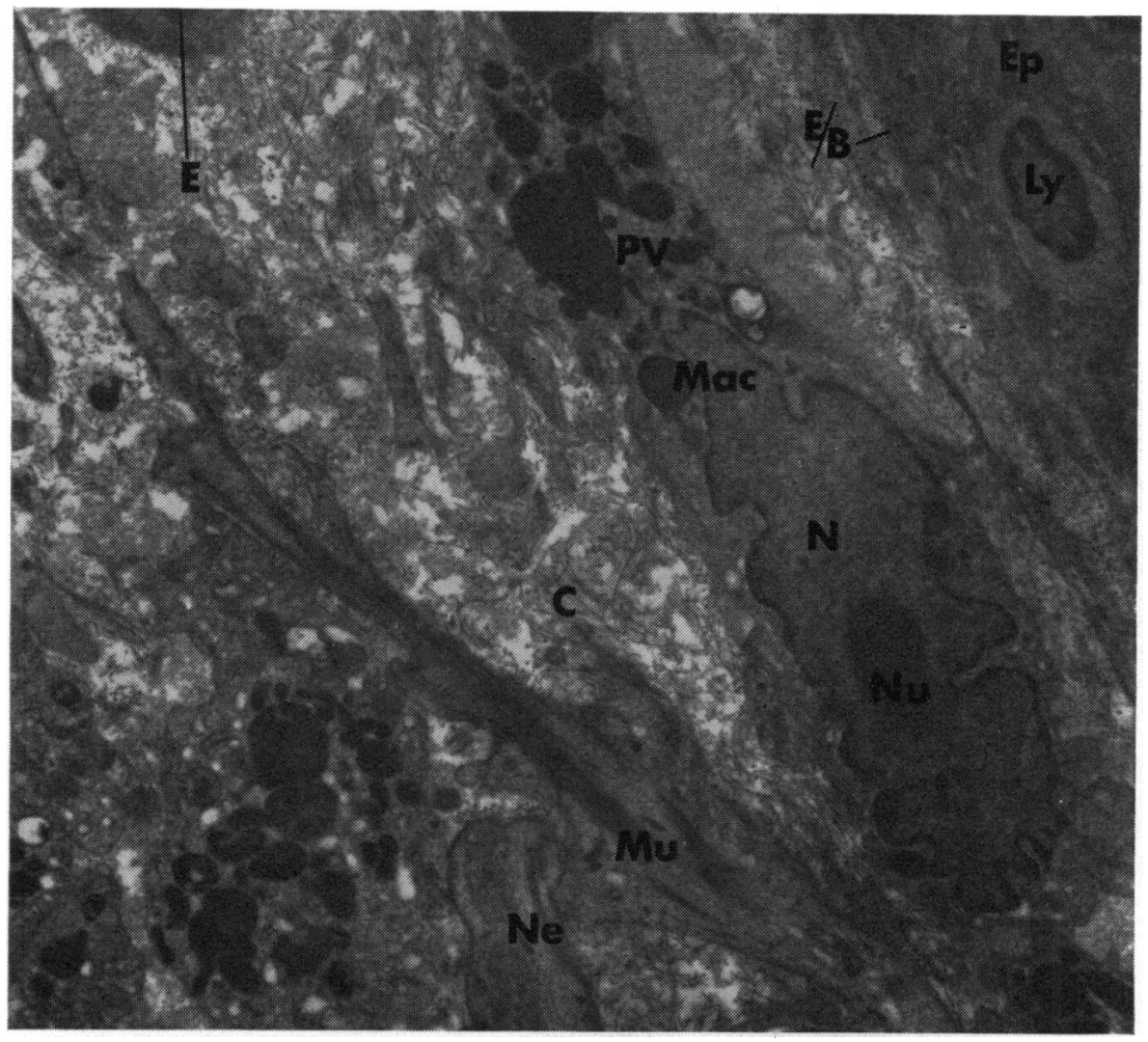

Fig. 2 Lamina propria of the human colon $(\times 7,000)$.

$\mathrm{Ep}=$ epithelium;

$\mathrm{E} / \mathrm{B}=$ epithelial basement

membrane; $\mathrm{Ly}=$ lymphocyte; $\mathrm{E}=$ endothelial nucleus: $\mathbf{C}=$ collagen; Mac = macrophage; $\mathbf{N}=$ nucleus; $\mathrm{Nu}=$ nucleolus; $\mathrm{Pv}=$ phagocytic vesicle; $\mathbf{M u}=$ muscle cell; $\mathrm{Ne}=$ nerve .

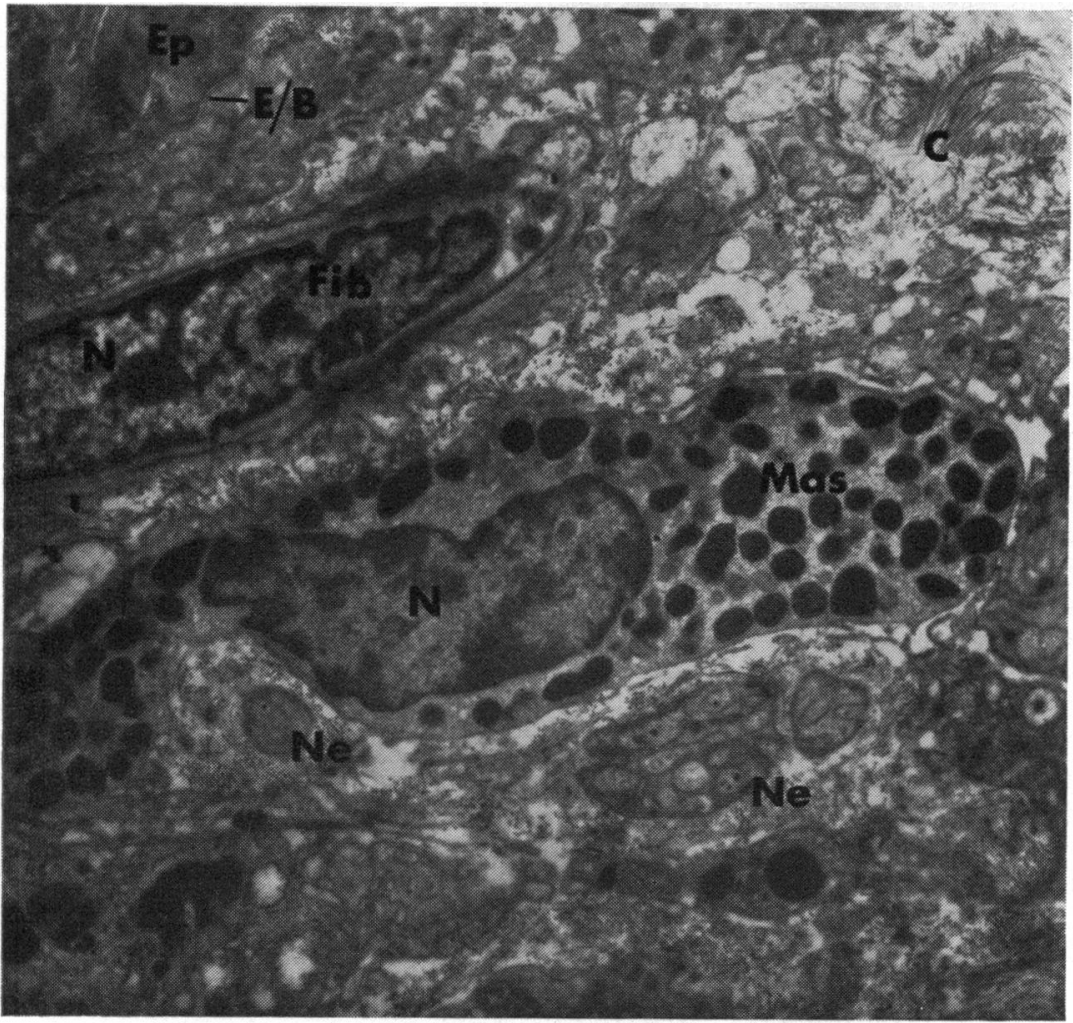

Fig. 3 Lamina propria of human colon $(\times 4,000)$. $\mathrm{Ep}=$ epithelium with basement membrane (E/B). In the lamina propria are mast cells with granules (Mas), fibroblasts (Fib), collagen (C) and nerves $(\mathrm{Ne})$, nuclei $(\mathrm{N})$. 


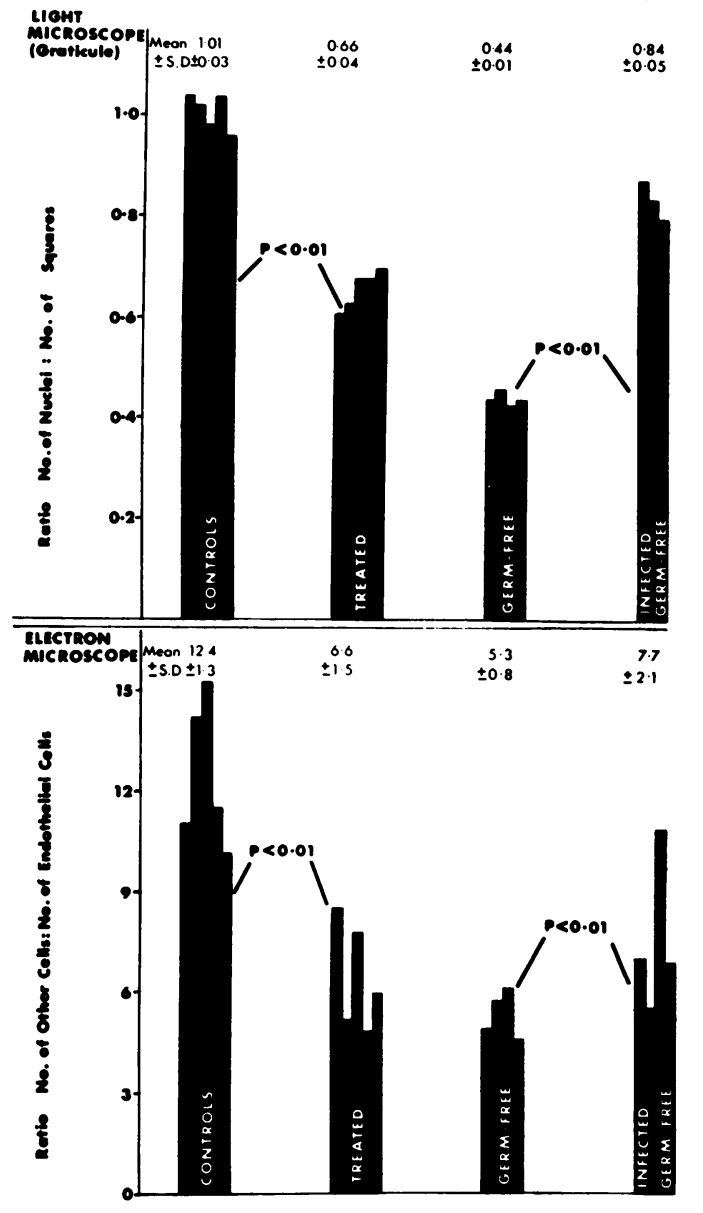

lymphocytes and plasma cells. These changes are less marked in the mice killed 28 hours after commencing treatment, but they were recolonized by staphylococci. In the diseased human lamina propria there is an increase of inflammatory cells.

The lamina propria of the human colon after neomycin shows the same changes as in the mice.

\section{THE EPITHELIUM}

The epithelia of the mouse and human colons are very similar. Principal and goblet cells are predominant (Fig. 6), with occasional argentaffin cells; and cells with many vesicles, a prominent Golgi zone, and deep-rooted microvilli, which appear to be a functional variant of the principal cells. Lymphocytes (Fig. 2), and 'crystal' cells resembling eosinophils are seen at all levels in the epithelium. The filamentous layer over the microvilli (Fig. 7) is the same in the germ-free and

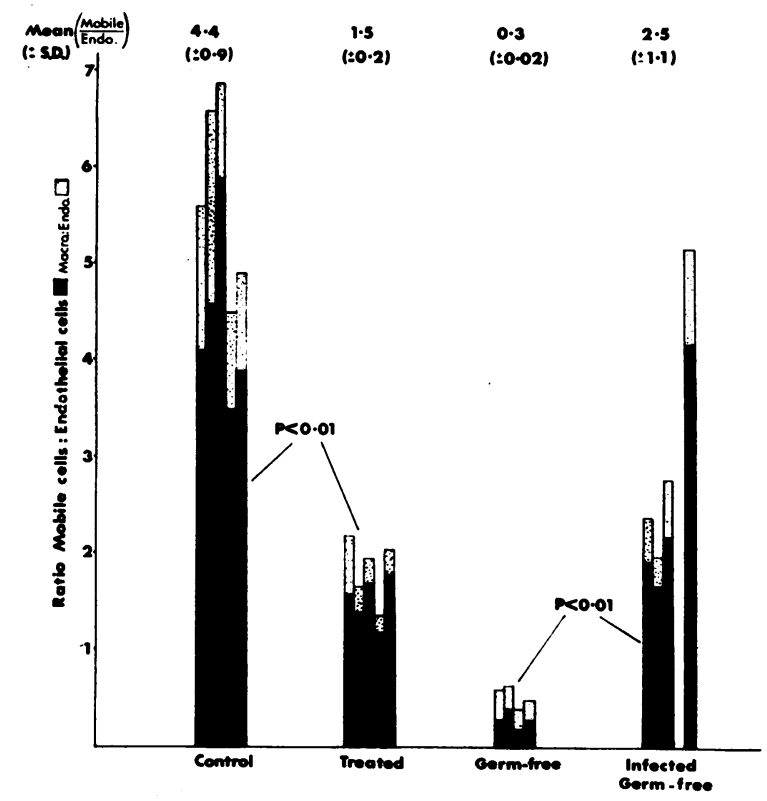

Fig. 4 Estimation of cellularity using the graticule (above) and the electron microscope. After disinfection with neomycin there is a reduction; the reverse change is observed when gnotobiotic mice are infected.

Fig. 5 The inflammatory cell content of the lamina propria. There is a marked reduction in the mice treated with neomycin.

conventional mice; the microvilli are about $30 \%$ longer in the gnotobiote. The human colonic microvilli are covered by filaments and tiny clubs (Fig. 6).

In the treated mice there appears to be increased cell loss. There is also evidence of epithelial damage (Fig. 8). In some cells, especially extruding ones, every mitochondrion is vesiculated, whereas none are in adjacent cells. Many cells have clear vesicles, which may represent intracellular oedema, and cytosegrosomes. No specific change is seen in the endoplasmic reticulum. The treated gnotobiotic and conventional mice show the same cell damage. The infected gnotobiotes show no changes. The filamentous layer is the same in all the mice. Some vesicles in the treated mice stain densely with osmium, but identical structures are seen in untreated mice.

Mitotic counts were studied to determine whether 


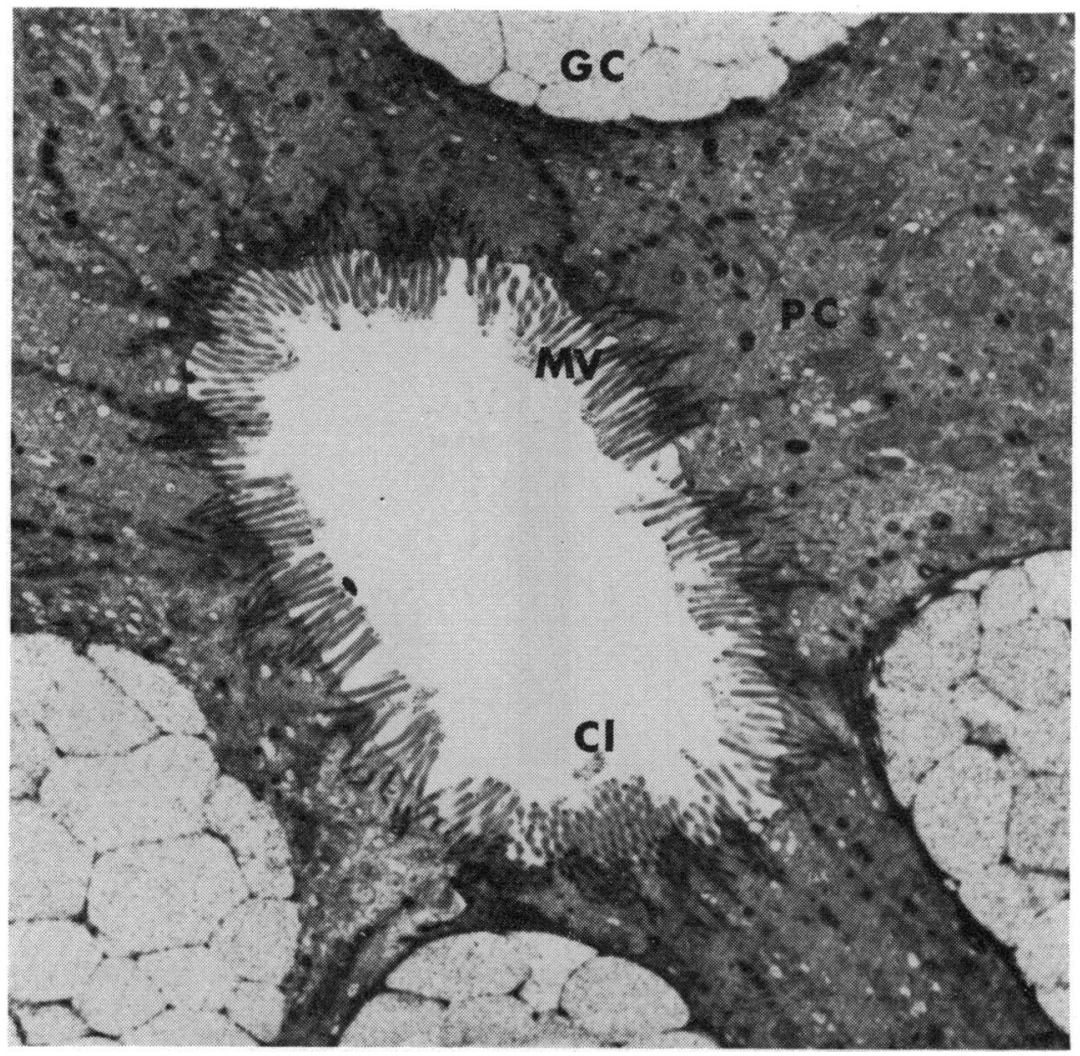

Fig. 6 Human colon $(\times 3,500)$. Transverse section of the superficial end of a crypt showing apical parts of principal cells (PC) with microvilli (MV) covered by filaments and clubs (CI); the goblet cells are full of globules of mucus (GC).

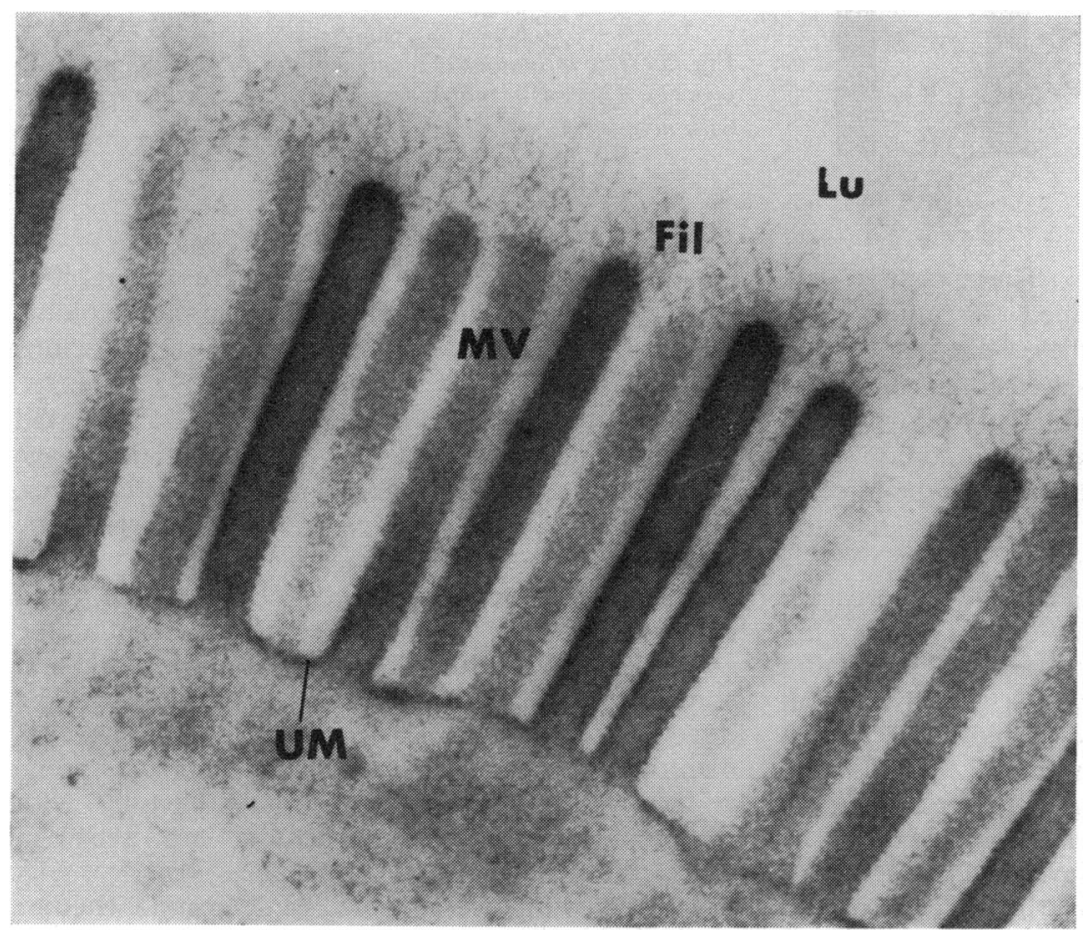

Fig. 7 Mouse colon (germ-free). $(\times 70,000$.) Microvilli (MV) on a principal cell covered by filaments (Fil). $\mathrm{UM}=$ unit membrane; $\mathrm{Lu}=$ lumen. 


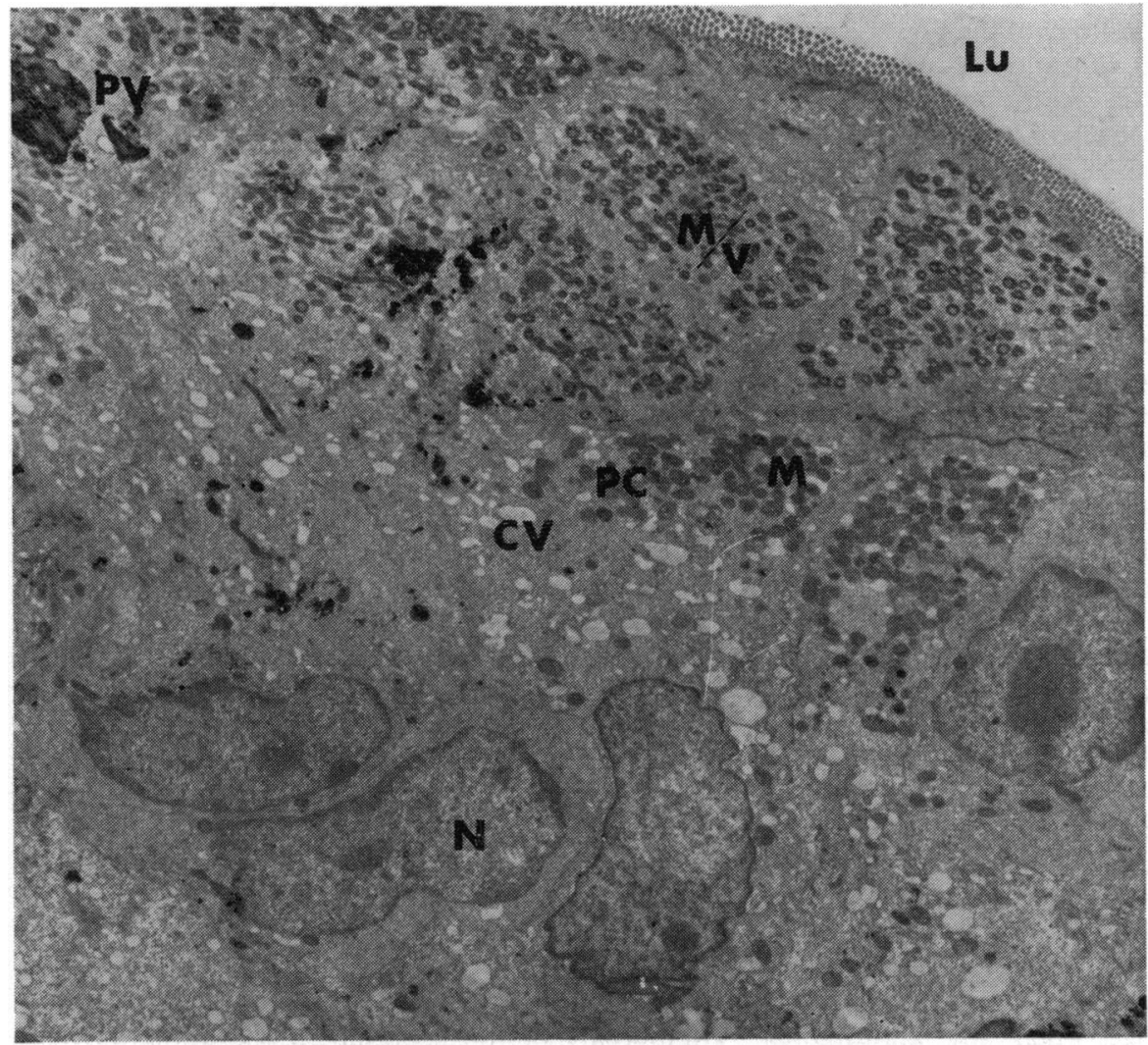

Fig. 8 Epithelium of $a$ mouse treated with neomycin $(\times 1,700)$. Lu = lumen; $\mathrm{N}=$ nucleus; $\mathbf{M}=$ normal mitochondria; $\mathrm{M} / \mathrm{V}=$ vesiculated mitochondria; $\mathrm{PV}=$ phagocytic vesicles; $\mathrm{CV}$ = clear vesicles.

an increased turnover rate caused the appearance of damage in the treated epithelium. There was, however, a significant increase in epithelial turnover time (from 52 to 72 hours) in the treated conventional mice (the duration of the mitotic cycle remained about one hour). When the gnotobiotes were given neomycin there was no change.

\section{THE CAECUM}

The caecums of the mice given neomycin were significantly enlarged, without gross histological change. The size of the large germ-free caecum was reduced by infection.

\section{Discussion}

THE LAMINA PROPRIA

The structures in the lamina propria are similar to those described by Donellan (1965) and Pascal, Kaye, and Lane (1968), but there is considerable variation in their disposition. The presence of lymphocytes, which Deane (1964) ignores, is important as they are involved in immunological mechanisms (Elves, 1966). The proportion of the cells is one of the more constant features.

The rapid reduction in the numbers of lymphocytes, plasma, and other inflammatory cells in the disinfected mouse is credible in view of the known turnover rate and mobility of these cells (Zweifach et al, 1965; Rusnyak, Foldi, and Szabo, 1967), and because the reverse changes quickly occurred in the infected gnotobiotes. This latter observation, and the evidence that germ-free animals resembling congenital gnotobiotes can be produced by using antibiotics (van der Waaij, 1968), suggest that the changes in the lamina propria are due to the alteration in bacterial flora and are not a toxic effect of neomycin.

Information about faecal bacteria could be carried to the lamina propria either by lymphocytes in the epithelium or by the movement of a chemical or bacterium across the epithelium, but bacteria were not seen in the lamina propria.

There is controversy about changes in the jejunal lamina propria after long-term neomycin (Dobbins, Herrero, and Mansbach, 1968); unfortun- 
ately reports on the bacteriology of the bowel are not included. The distension of endoplasmic reticulum in plasma cells may be the result of a similar action to that of the drug on bacterial ribosomes (Leon and Brock, 1967).

\section{THE EPITHELIUM}

The findings in normal epithelium are similar to those of Pittman and Pittman (1966) and many others (see Aluwihare, 1969).

The variation in the morphology of the filamentous layer (and basement membrane) was the same in all the mice and human epithelium, and it is unlikely to be dynamically involved in the antibacterial defences of the colon (cf Donellan, 1965). No important differences were found in the mitochondria or endoplasmic reticulum of the germ-free mice (Nakao and Levenson, 1967; cf Kenworthy, 1968). The mitochondrial vesiculation in the treated mice accords with the damaging effect of neomycin on mitochondria (Friedman, Dadswell, and Bird, 1966). The dense globules in epithelial cells cannot represent neomycin (cf Dobbins et al, 1968) since they were seen in all the mice.

Signs of epithelial damage were seen in conventional and gnotobiotic mice and must therefore be a direct effect of the drug. This might be via increased cell turnover, but there is a fall in the mitotic count after neomycin due to the change in flora since there is no change when the gnotobiotes are treated. The latter findings are to be expected since the normal faecal flora stimulate epithelial turnover (Abrams, Bauer, and Sprinz, 1963). Mitotic arrest was not seen (cf Dobbins et al, 1968). The epithelial cell vacuolation, increase in caecal size, and faecal fluidity may be due to a disturbance in water absorption (Savage and Dubos, 1968).

THE DEFENCES OF THE COLON AND SURGICAL PRACTICE

The resistance of mice to oral and parenteral infection can rapidly be reduced by altering the faecal flora with antibiotics (Dubos and Schaedler, 1960; Dineen, 1961). Conversely, the susceptibility of gnotobiotes can be reduced by precolonizing them with commensals (Sprinz, Kundel, Dammin, Horowitz, Schneider, and Formal, 1961). Macrophages in gnotobiotes are less efficient than conventional controls (Bauer, Horowitz, Levenson, and Popper, 1963). It appears that animals have a general resistance to disease which can rapidly be diminished by reducing the faecal flora. The basis for this mechanism is probably provided by the cells in the lamina propria, the reduction in the numbers of lymphocytes and other inflammatory cells accompanying disinfection being the structural counterpart of the equally rapid changes in resistance. Similar changes in the human colon may be responsible for the 'superinfections' that can follow antibiotic preparation for colectomy (Poth, 1952). A local reduction in resistance may render the cut edges of the bowel more liable to disruption by surviving bacteria and could also account for the increase in recurrence of carcinoma at the suture line in the human and experimental animal (Cohn, 1964) following the use of antibiotics orally. Heneghan (1968) found that the susceptibility of germ-free animals to intraperitoneal tumour implantation could be reduced by colonizing the bowel with bacteria beforehand. The normal faecal flora, via the inflammatory cells in the lamina propria, may therefore confer on the host a local and general 'antipathogenic' resistance by a humoral or cellular mechanism.

The epithelial changes are not important because healing depends initially on granulation tissue, and a large dose of neomycin was necessary. However, neomycin can inhibit fibroplasia (Brotzu, 1962), and colonic healing in rats (Woodward, Herrmann, Shadomy, and Pulaski, 1964).

\section{Conclusions}

The reduction in the number of inflammatory cells in the colonic lamina propria is the structural counterpart of the lowering of the antipathogenic resistance of the host when there is interference with the faecal flora. These cells probably constitute the most important and only dynamic morphological part of the defences of the colon. In view of the controversy about the place of antibacterial agents before colectomy, it would seem advisable to re-evaluate the place of colonic antisepsis using adequate numbers of patients, controlling all variables, including faecal consistency and loading, and considering long- and short-term prognosis, before continuing routinely to use these powerful drugs.

I am indebted to Professor G. Causey for his constant help, and to the staff of the Anatomy Department of the Royal College of Surgeons of England, particularly Mr S. A. Edwards, Mr and Mrs R. Hutchings, Miss E. Griffin, and Miss M. Gill.

I am grateful to Mr A. Parks of St Marks and the London Hospitals for the specimens of human colon, Dr D. K. Blackmore of the MRC, Carshalton, for his advice and for providing the germ-free animals, the staff of the College library, and the animal house; and Boots Pure Drug Company for the neomycin.

This work was done during the tenure of a 
Bernard Sunley fellowship, and formed the basis of a thesis accepted as part of the requirements for the degree of MChir (Cantab).

\section{References}

Abrams, G. D., Bauer, H., and Sprinz, H. (1963). Influence of the normal flora on mucosal morphology and cellular renewal in the ileum. Lab. Invest., 12, 355-364.

Aluwihare, A. P. R. (1969). The effect of neomycin on the colon. M.Chir. Thesis, Cambridge.

Baker, F. J., and Bream, M. R. (1967). Handbonk of Bacteriological Technique. Butterworths, London.

Bauer, H., Horowitz, R. E., Levenson, S. M., and Popper, H. (1963). The response of the lymphatic tissue to the micrebial flora. Amer. J. Path., 42, 471-483.

Hill, A. B. (1966). Principles of Medical Statistics. Lancet, London.

Brotzu, G. (1962). Cytotoxic and cytostatic action of various antibiotics. Minerva chir., 17, 1254-1257.

Causey, G. (1962). Electron Microscopy. Livingstone, London.

Cohn, I., Jr. (1964). Recurrence of carcinoma after colon surgery. Maryland med. J., 13, 45-48.

Corrin, B., Clarke, A. E., and Spencer, H. (1969). Ultrastructural localization of acid phosphatase in the rat lung. J. Anat. (Lond.), 104, 65-70.

Davenport, H. A. (1960). Histological and Histochemical Technics. Saunders, Philadelphia and London.

Deane, H. W. (1964). Some electron microscopic observations on the lamina propria of the gut, with comments on the close association of macrophages, plasma cells, and eosinophils. Anat. Rec., 149, 453-473.

Dineen, P. (1961). The effect of neomycin bowel preparation on the susceptibility to systemic Staphylococcal infection. Surgery, 49, 727-730.

Dobbins, W. O., Herrero, B. A., and Mansbach, C. M. (1968) Morphologic alterations associated with Neomycin induced malabsorption. Amer. J. med. Sci., 255, 63-77.

Donellan, W. L. (1965). The structure of the colonic mucosa. Gastroenterology, 49, 496-514.

Dubos, R. J., and Schaedler, R. W. (1960). The effect of the intestinal flora on the growth rate of mice and on their susceptibility to experimental infections. J. exp. Med., 111, 407-417.

Elves, M. W. (1966). The Lymphocytes. Lloyd-Luke, London.

Friedmann, I., Dadswell, J. V., and Bird, E. S. (1966). Electronmicroscope studies of the neuroepithelium of the inner ear in guinea-pigs treated with neomycin. J. Path. Bact., 92 415-422.
Hally, A. D. (1964). A counting method for measuring the volume of tissue components in microscopical sections. Quart. J. micr. Sci., 105, 503-514.

Heneghan, J. B. (1968). Ehrlich ascites tumour growth in gnotobiotic mice. In Advances in Germ-Free Research and Gnotobiology, edited by M. Miyakawa and T. D. Luckey. Iliffe Books, London.

Kaye, G. I., Lane, N., and Pascal, R. R. Colonic pericryptal fibroblast sheath. II. Gastroenterology, 54, 852-865.

Kenworthy, R. (1968). Mild physiologic inflammation of conventional life. In Advances in Germ-Free Research and Gnotobiology, edited by M. Miyakawa and T. D. Luckey. Iliffe Books, London.

Lancet (1970). Editorial The colon and the surgeon. Lancet, 1, 509-510.

Le Blond, C. P., and Stevens, C. E. (1948). The constant renewal of the intestinal epithelium in the albino rat. Anat. Rec., 100, 357-377.

Leon, S. A., and Brock, T. D. (1967). Effect of streptomycin and neomycin on physical properties of the ribosome. J. molec. Biol., 24, 391-404.

Nakao, K., and Levenson, S. M. (1967). Atypical mitochondrial morphology of the intestinal absorptive cells of the germ-free rat. Experientia (Basel), 23, 494-496.

Parker, R. B. (1965). Pipette count method for obligate anaerobes. Appl. Microbiol., 13, 1042.

Pascal, R. R., Kaye, G. I., and Lane, N. (1968). Colonic pericryptal fibroblast sheath I. Gastroenterology, 54, 835-851.

Pittman, F. E., and Pittman, J. C. (1966). An electron microscopic study of the epithelium of normal human sigmoid colonic mucosa. Gut, 7, 644-661.

Poth, E. J. (1952). Intestinal antisepsis. West. J. Surg., 60, 205-210.

Rusnyak, I., Foldi, M., and Szabo, G. (1967). Lymphatics and Lymph Circulation. Pergammon Press, Oxford.

Savage, D. C., and Dubos, R. (1968). Alterations in the mouse cecum and its flora produced by antibacterial drugs. J. exp. Med. 128, 97-110.

Sprinz, H., Kundel, D. W., Dammin, G. J., Horowitz, R. E., Schneider, H., and Formal, S. B. (1961). The response of the germ-free guinea pig to oral bacterial challenge with E. coli and Shigella flexneri. Amer. J. Path., 39, 681-695.

van der Waaij, D. (1968). Production of bacteria free mice by antibiotic decontamination. In Advances in Germ-Free Research and Gnotobiology, edited by M. Miyakawa and T. D. Luckey. Iliffe Books, London.

Woodward, S. C., Herrmann, J. B., Shadomy, S., and Pulaski, E. J. (1964). Oral neomycin and the healing of colonic anastomoses in the rat. Surg. Gynec. Obstet., 119, 799-806.

Zweifach, B. W., Grant, L., and McCluskey, R. T. (1965). The Inflammatory Process. Academic Press, New York. 